\title{
A Semantic Network and Categorical Content Analysis of Internet and Online Media Research
}

\author{
Sungjoon Lee ${ }^{1}$, Jang Hyun Kim*,2 and Devan Rosen ${ }^{2}$ \\ ${ }^{1}$ Communications Policy Research Center (CPRC), Yonsei University; ${ }^{2}$ Department of Speech Communication, \\ University of Hawaii at Manoa
}

\begin{abstract}
This study examines the growth of new media and Internet research from 1991 to 2005. A multi-method approach using both semantic network and categorical content analysis of research abstracts from published manuscripts in ComAbstracts was performed to reveal the occurrence of relevant keywords and parallel theoretical development over time. The categorical content analysis found that 1) Internet and new (online) media studies have not been successful in finding underdeveloped or possible future uses of media although they have rapidly increased their volume, and that 2) traditional research agendas including effect, use, and development of media have been frequently studied. Semantic network analyses revealed that meaning clusters of Internet research abstracts are composed of 1) social aspect and 2) issue-based and policy agendas. The current research expanded previous analyses by using a greater number of keywords, an extended time frame, dual methods, and a more comprehensive coverage of academic journals.
\end{abstract}

\section{INTRODUCTION}

Since its inception, the Internet has increasingly been an integral part of human life, including economic, political, and social behavior (Wellman \& Haythornthwaite, 2002). Data indicate that Internet users have grown in number from 16 million 1995 to 1.6 billion as of 2009 (Internet World Stats, 2009). Users spent an average of 32 minutes a day online in December 2002, which almost doubled to 54 minutes a day by February 2007 (Nielsen/Net Ratings, 2007). Along with increased use, the Internet has penetrated into our daily life through a rapidly expanding communicative functions and technologies, such as email, instant messaging (IM), weblog (blogs), voice over Internet (VoIP), Internet Protocol Television (IPTV), webcasting, and computer supported collaborative work and learning. The Internet is changing communication from a "broadcast" structure to a "netcast" structure (Bonchek, 1997) ${ }^{1}$.

Given the impact of Internet technologies on human communication, scholars in Communication have shown increasing interest in the Internet and other new media. Lee and Barnett (2005) found that the Communication Technology division of the International Communication Association (ICA) achieved greater growth compared to all other divisions between 1991 and 2005. Along with this trend, new journals dedicated to the examination of the Internet and other new media have emerged, such as the Journal of Computer-Mediated Communication from 1995

*Address correspondence to this author at the Department of Speech, University of Hawaii at Manoa, 2560 Campus Rd, Honlolulu, HI, 96822, USA; Tel: (808) 956-3323; Fax: 808 -956-3947; E-mail: jangkim@hawaii.edu

\footnotetext{
${ }^{1}$ The Internet is also changing the consumers' purchasing behavior from the traditional retail shopping to e-commerce. According to the U. S. Census Bureau (2006), ecommerce accounted for $2.76 \%$ of total retail sales in the U. S. in 2006 compared to $0.91 \%$ in 2000 . In the political arena, the Internet is changing communication from a "broadcast" structure to a "netcast" structure (Bonchek, 1997).
}

and New Media and Society published from 1998. How the Internet can change the traditional system and media became an important agenda for research (Kim \& Weaver, 2003). Thus, it is worth exploring what kinds of research have been conducted in regard to the Internet and the relevant communication technologies.

The discussion on how and why the Internet should be examined from a communication perspective date back to an issue in the Journal of Communication (Vol. 46 Issue 1, 1996). It included articles on how traditional mass communication theoretical frameworks can be applied to this new medium (Morris \& Ogan, 1996) and the basic unit of analysis of Internet communication (Newhagen \& Rafaeli, 1996). "How and Why" issues of Internet research have been considered one of the major agendas of communication research (Caplan, 2001; Stempel \& Stewart, 2000; Weaver, 2000).

Previous studies show several findings: First, the Internet challenges the applications of the traditional theoretical models in the mass communication field. Morris and Ogan (1996) stated, "the Internet is a multifaceted mass medium....Its varied forms show the connection between interpersonal and mass communication that has been an object of study since the two-step flow associated the two" (p. 42, italics added). Shaw et al. (2000) claimed that traditional mass communication theories need to be redefined to explain the Internet and new media effectively.

Second, the use of Internet technologies also challenges traditional methods of research. Methodologies used for the traditional linear communication model have been questioned since the advent of the Internet (Newhagen \& Rafaeli, 1996). Unique characteristics of the Internet, such as hypertext, cannot be explained by traditional approaches based on the linear communication effect model (Newhagen \& Rafaeli, 1996). Another methodological challenge is sampling. Stempel and Stewart (2000) argued that Internet 
research should not rely on conventional sampling procedures because they were developed to find specific types of users from an identifiable population. "There is no existing sampling frame that lists all the personal pages on the web" (Dominick, 1999, p. 649). Further, there is no uniform unit of analysis in Internet research, which makes any theoretical integration in Internet research difficult (December, 1996).

To understand the impact of the Internet on communication scholarship, a review of existing studies of research trends reveals several shortcomings. These studies examined periods only up to the late 1990s, used limited keywords for searching, and employed homogeneous methods (categorical content analysis) and few sources (a limited number of journals). The current study is more comprehensive than past studies by using increased keywords for searching relevant studies, expanding the time frame to 1991-2005, and examining more academic journals than existing research trend studies. Moreover, our study provides an integrated understanding of recent developments in the Internet and new media literature by taking advantage of dual methodologies including semantic network analysis and categorical content analysis.

The present study aims to examine the changes of Internet and new media studies focusing on the research topics, the method(s) employed, and the theoretical frameworks used. The patterns in the Internet-related research are also discussed with a theoretical four-phase development model of communication research, as suggested by Wimmer and Dominick (2000). By doing this, the current study suggests possible directions for future communication research.

\section{LITERATURE REVIEW}

\section{Existing Literature on the Trend of the Internet and New (Online) Media Research}

Kuhn (1970) posited that shared scholastic viewpoints and practices among scholars, and the reinforcement of them, lead to the process of "paradigm" construction. By paradigm, scholars tend to formulate similar cognitive and intellectual approaches to their shared research agendas (Kuhn, 1970). Through the construction of academic organizations such as the International Communication Association, and publication of journals such as Journal of Communication, scholars generate and distribute knowledge and indicate shared trends of scholarship (Cappell \& Guterbock, 1992). Political or economic factors from government or other political/legal circumstances, the social status of scholars, ideational difference, and the formation of intellectual circles among scholars and their students (Cappell \& Guterbock, 1992) broadly influence this process. In this context, citation analysis and shared memberships research have been widely used in the field of communication to investigate the research trend (Reeves \& Borgman, 1983; Rice et al., 1988). Also, the examination of the topical and semantic structure of past literature should help us understand the state of Internet and online media scholarship.

Several previous studies have examined Internet research trends in communication. Tomasello (2001) examined
Internet-related research in five leading communication journals including Communication Monographs, Human Communication Research, Journal of Communication, Journalism and Mass Communication Quarterly, and Journal of Broadcasting and Electronic Media. The study covered articles from 1994 to 1999. Findings indicated that the overall percentage of the Internet-related studies per issue increased over time. Kim and Weaver (2002) reported more recent trends by investigating articles published from 1996 to 2000. They categorized Internet research into 12 broad categories such as legal and policy issues, cultural issues, and education/instructional applications and found out that law and policy issues and uses and perception of the Internet were the most frequently studied issues during the period. They also applied a four-phase evolutionary model of Internet research (Wimmer \& Dominick, 2000), the details of which will be explicated in the Categorical Content Analysis section below. Cho and Khang (2006) conducted a similar study covering the period from 1994 to 2003. They reported that around $13 \%$ of research articles in communication, advertising, and marketing were related to Internet topics. Woo (2005) conducted trend research on Internetrelated studies in Korea between 1995 and 2005 and compared his findings to Kim and Weaver (2002). Woo found out that Korean studies' reliance on quantitative research was higher than that of the United States, and most Korean Internet studies lean on descriptive rather than theory-centered research. Woo also concluded that research topics in Korea were skewed more toward the technological nature of Internet itself than those in the United States.

The present study expands the literature covered in terms of time frame and topics. First, it covers a wider range of time from 1991 to 2005 . The studies by Tomasello (2001) and Kim and Weaver (2002) were limited because they did not include research from the year 2000, when rapid and wide adoption of the Internet occurred. Second, it uses a more comprehensive dataset of research articles. For example, although Cho and Khang's (2006) study covered the period from 1994 to 2003, their research dealt only with selected 15 major journals including Journal of Communication, Journal of Advertising and Journal of Marketing. Most previous studies selected journals based on the researchers' discretion or utilized limited "keywords" in the process of searching literature. For instance, Kim and Weaver (2002) used only "Internet" and "World Wide Web" as keywords for searching, excluding CMC (computermediated communication), which may have missed the studies analyzing online communication behaviors such as email exchanges. Therefore, the present study used a wider range of keywords as listed in the Method section below.

Finally, the current study goes beyond categorical content analysis with an addition of semantic network analysis. Existing trend research has used human-coded content analysis, and it relied mainly on effect (e.g., correlations between variables) across a wide number of studies, which is conventionally known as "meta-analysis." However, by combining traditional content analysis and semantic analysis, the validity of this study increases as it provides a more integrated view of the current status of Internet research. Combining the two methodologies can help to compensate for each method's weaknesses by 
increasing the reliability of analysis and minimize the detachment from textual context (Krippendorf, 2004).

\section{An Analysis of Past Studies Using a Semantic Network Analysis}

The current research uses semantic network analysis to examine the trends in new media and Internet research agendas at the word level. Monge and Eisenberg (1987) helped to introduce the idea of semantic networks to the field of communication. Two words have a tie in a semantic network if their uses are related. Relations among words are identified by distance, co-occurrence, and frequency.

Semantic network analysis has its roots in cognitive science literature, which argued that people have a structural meaning system in memory (Collins \& Quillian, 1972). For instance, Barnett and Woelfel (1988) illustrated how a spatial model can represent meaning as the relationships among words. To analyze the perceptions of a group of people, convergence theorists (Barnett \& Kincaid, 1983; Rogers \& Kincaid, 1981) claimed that a common set of meanings emerges over time through interactions among individuals. Contagion theorists (Carley, 1991; Carley \& Kaufer, 1993) argue that the more networked members are exposed to one another over time, the more similar their beliefs, assumptions, and attitudes become. Along this line of thought, semantic network theorists have argued that shared words and meanings in academic publications can emerge among communication scholars of shared scientific interests (Doerfel \& Barnett, 1999; Park \& Leydesdorff, 2009; Rice, 2005; Stephen, 1999). Based on existing literature, this study assumes that scholars' mental structure and attitudinal characteristics can be analyzed by examining texts such as research articles (Barnett \& Woelfel, 1988; Doerfel \& Barnett, 1999; Stephen, 1999).

Rice (2005) used semantic network analysis to examine trends in new media and Internet topics using conference session titles, paper titles, and abstracts of the annual convention of Association of Internet Researchers (AoIR), a large group of the Internet researchers. He examined core concepts and relationships among them. His findings indicated that semantic clusters in 2003 included digital access, knowledge management, e-governance, and e-health. In 2004, open source collaboration, electronic campaigns, social networks, and community were major concepts comprising semantic clusters. However, his study was limited to the two years (2003 and 2004). In this study, the period of coverage is extended from 1991 to 2005, so that the changing patterns in research over time can be clearly identified. In addition, Rice's (2005) study was confined to the AoIR, thus it does not represent Internet researchers of the communication discipline. In contrast, the current study uses a wider data set, ComAbstracts.

Using ComAbstracts does not mean that this study negates the interdisciplinary nature of Internet and new media scholarship. Abstracts from ComAbstracts encompass the studies from close disciplines such as psychology, information science, and sociology. See note \#2 for details.

\section{RESEARCH QUESTIONS}

Based on the literature examined above, the current study poses the following research questions:
RQ1: What is the thematic, theoretical, methodological, and a four-phase developmental status of Internet and new media-related research revealed by a categorical content analysis during the period from 1991 to 2005?

RQ2: What is the topical and semantic status of Internet and new media-related research revealed by a semantic network analysis?

\section{METHOD}

\section{Data}

Data were gathered from Communication Abstracts (or ComAbstracts, retrieved from http://www.cios.org/www/abstract.htm) using keywords in the subject index. The keywords used in this study include: Computer-mediated communication (CMC), cyber, cyberspace, human-computer interaction (HCI), information and communication technology, information, computer, interactivity, digital, electronic, Internet, Web, Weblog, blog, webpage, website, World Wide Web (WWW), online, network, presence, technology, online, social capital, bonding, and binding. The keywords were selected to maximize the inclusion of any literature related to the Internet and new (online) media, and included plural or abbreviated forms of each word as well. ComAbstracts includes the majority of studies relevant to communication. The journals included in the database encompass 144 journals in communication and relevant disciplines including Journal of Communication, Human Communication Research, and Journal of Applied Communication Research. A detailed journal list is available at http://www.cios.org ${ }^{2}$. Data gathered from ComAbstacts include information related to articles such as author, author's affiliation, publishing journal, year of publication, titles and abstracts. Then, only the abstracts and titles in all of the articles were extracted from the data, excluding information regarding author, author's affiliation, publishing journal, year of publication. Duplicated information (e.g., overlapping abstracts) between different keywords was included in the data only once. In addition, after reviewing data, the information that was not relevant to the Internet or online media based on researchers' discretions was excluded from the analysis. For example, some studies that mainly focused on traditional media rather than the Internet, found with the keyword "information," were omitted. The intercoder reliability (Scott's $\Pi$ ) of three coders in discarding these irrelevant articles were 0.82 , but with a close reexamination and discussion, all the discrepancy between

\footnotetext{
${ }^{2}$ Journals related to Internet and new media searched through CIOS (ComAbstracts) are 144 including: Advances in Discourse Processes, Advances in Telematics, Asian Journal of Communication (0129-2986), Canadian Journal of Communication (07053657), Communicatie (0771-7342), Communication (0305-4233), Communication and Critical/Cultural Studies (1479-1420), Communication Law and Policy (1081-1680), Communication Monographs/Speech Monogra-phs (0363-7751), Communication Quarterly/Today's Speech (0146-3373), Communication Reports (0893-4215), Communication Research (0093-6502), Commun-ication Research Reports (08824096), Communication Review (1071-4421), Communication Studies/Central States Speech Journal (1051-0974), Communication Theory (1050-3293), Communication Yearbook, Comm-unications: The European Journal of Communication Research (0341-2059), Convergence (1354-8565), Cri-tical Discourse Studies (1740-5912), Discourse and Society (0957-9265), Discourse Processes (0163-853X), Electronic Journal of Communication (1183-5656), European Journal of Communication (02673231), Global Media and Communication (1742-7665), Health Communication (10410236), Howard Journal of Communication (1064-6175), Human Communication Research (0360-3989), Information Communication \& Society (1369-118X), International Journal of Press/Politics (1081-180X), International Journal on Media Management (1424-1277), and so on. See CIOS website for details.
} 
the coders was resolved. After these several procedures, the data yielded a total of 1,277 articles (or abstracts and titles) and these were analyzed for the study.

\section{Categorical Content Analysis}

Each publication was coded for year of publication, research topic, development of research based on Wimmer and Dominick's (2000) classification, mainly used theory (or theories), and methodology. Overall, frameworks by Wimmer and Dominick (2000) and Kim and Weaver (2002) were used as coding guidelines. The classification of Internet and new media research was reexamined and confirmed by a pilot study using 50 articles randomly chosen from the samples, which involved three coders. The inter-coder reliabilities (Scott's $\Pi$ ) for each coding item were 0.83 (research topic), 0.85 (development of research), 0.74 (communication theory), and 0.87 (methodology), but through discussion among coders and the authors, all discrepancies the coders had were resolved. The detailed procedures for each coding item are presented below.

\section{Research Topics}

The research topic refers to the main themes (topics) that the authors of articles aimed to describe in their publications. Most coding categories for the topics were based on Kim and Weaver's (2002) classifications, which is the most comprehensive classification to date. One of their categories labeled "the evolution of websites" was classified to a different category (INTUSE) in this study. The categories employed are as follows:

- Law and policy issues in general (LAWPOL)

- Uses and perception of the Internet and new media, tele-medics (INTUSE)

- Economic, advertising and marketing issues (ECOAD)

- Politics, democracy, and development issues (POLDEV)

- Cultural and social issues (CULSOC)

- Historical or philosophical discussions (HISTPHI)

- Effects of the Internet on individuals or organizations (EFFECTS)

- Technical issues in general, issues of specific tool applications (COMTEC)

- Education and instructional application, distance learning (EDUCAT)

- ssues about Internet research, improvement of Internet research (INTISS)

- Other issues (OTHISS)

\section{Developmental Phases of Research}

The current study utilized Wimmer and Dominick's (2000) suggestion to track the longitudinal evolution of communication scholarship. Wimmer and Dominick state that communication scholars tend to examine new media from the perspective of four-phase evolution over time since each medium's introduction. They defined what the characteristics of each of four phases are as follows: In the first phase, scholars' interests are focused on the medium itself, and are driven by the following questions: What is the nature of the medium? How does it work? What technologies are relevant in its use? (Wimmer \& Dominick, 2000) In the second phase, scholars are more interested in the uses and the usage patterns of the media. Example questions in this context are: What are the major purposes for using this medium? Who are the major user groups? How do people perceive this new medium? The third phase can be characterized by research focusing on the social and psychological effects of the medium, as illustrated by the following question: How does the medium affect personal lives, organizations and society? In the last phase, scholars talk more about how the medium can be improved, how it can contribute to our society, and more advanced applications of the new medium such as webcasting (Wimmer \& Dominick, 2000). Kim and Weaver (2002) employed this model to analyze longitudinal changes of the Internet/new media research from the perspective of fourphase development during the years 1995-2000. They found out that the first two phases of research dominated Internet research agenda. In other words, there was far more research on the uses and users of the Internet than on its effect or its improvement.

\section{Theoretical Background}

For each abstract, theoretical frameworks mainly used were coded. Several previous studies (Cho \& Khang, 2006; Cooper, Potter, \& Dupagne, 1994; Kim \& Weaver, 2002; Riffe \& Freitag, 1997) suggested that salient theoretical framework(s) should be treated as a variable in the analysis of communication research trends. In this study, a theory is defined as a systematic explanation in the hypotheticodeductive sense where a general proposition is identified, and an empirical test is conducted to determine if there is support for the hypothesis (Cooper et al., 1994). In other words, the "presence of explicit hypotheses or research questions" (Riffe \& Freitag, 1997, p. 517) was used as an important criterion to determine whether an article used a theoretical framework. Each abstract was evaluated in terms of whether there was a clear mention of a specific theory (theories) with explicit hypotheses and/or research questions. If the salient utilization of a theory was unclear based on the abstract, the authors printed the original published manuscript to evaluate it more closely.

\section{Methodologies Used}

The specific methodology (or methodologies) used for each study was identified and coded based on the categorization by Kim and Weaver (2002) and Wimmer and Dominick (2000). Also, the first criterion of classification included whether a qualitative or a quantitative methodology was utilized (Lindlof \& Taylor, 2002; Wimmer \& Dominick, 2000). A quantitative study can be defined as an article using number figures including descriptive statistics (e.g., data in means and percentages) and/or inferential statistics for the purpose of generalization to a larger population, as suggested by Wimmer and Dominick (2000). Online or offline surveys, content analysis, lab experiments, and studies based on empirical secondary data may be classified as quantitative research (Cooper et al., 1994). On the other hand, a qualitative study can be defined as an article that has the following characteristics (Lindlof \& Taylor, 2002): 


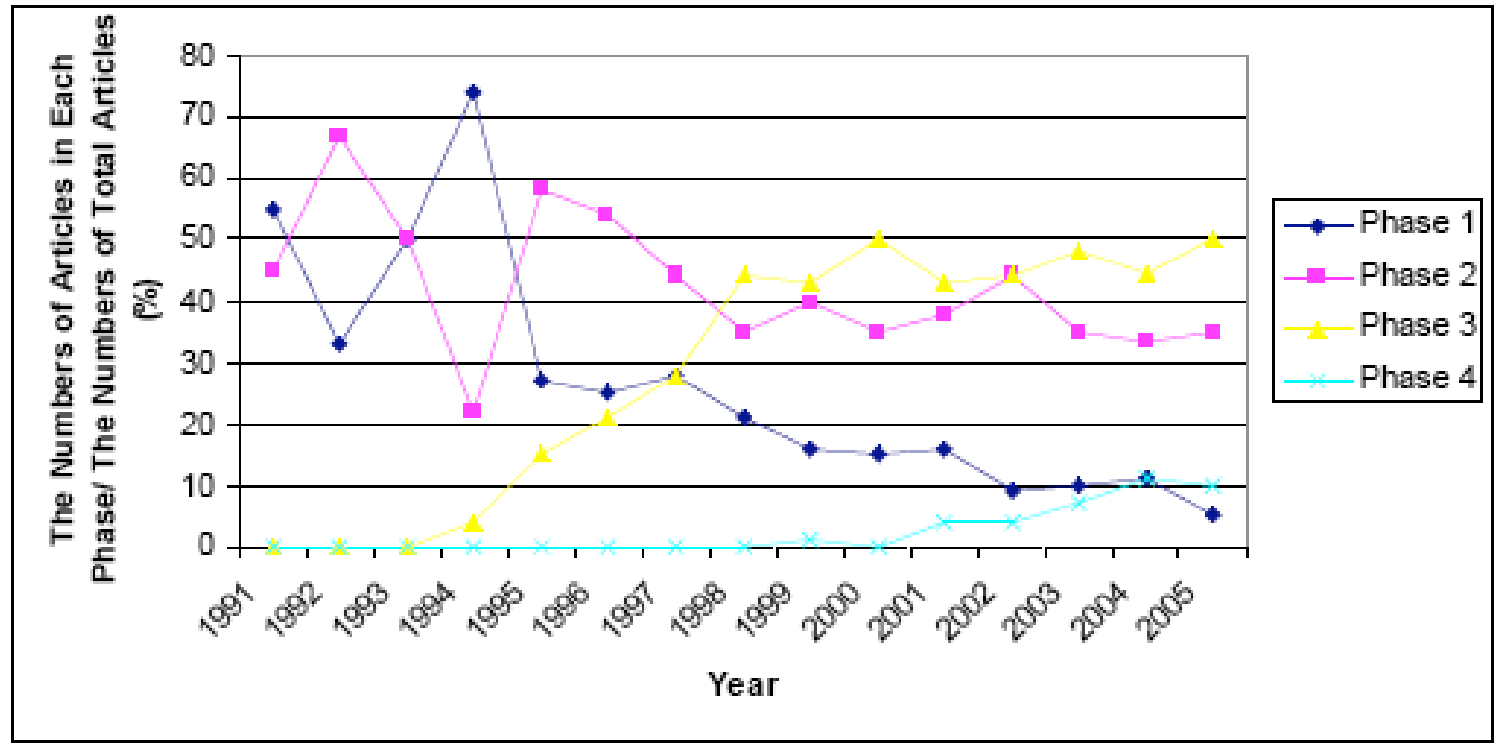

Fig. (1). The changing percentage for each phase in Wimmer and Dominick's (2000) developmental model of internet and new media research over time.

- Theoretical interest in human interpretational processes

- Using human investigator as the primary research instrument

- Relying primarily on narrative forms for coding data and writing the texts to be presented to audience.

The major difference between a qualitative and quantitative study is that a qualitative study does not rest its evidence on the logic of mathematics, the principle of numbers, or the methods of statistical analysis (Anderson \& Meyer, 1998). In this regard, analyses of issues and problems ${ }^{3}$ using discourse analyses were coded as qualitative research. If the method used was unclear, the authors retrieved the original manuscript and confirmed it.

\section{Semantic Network Analysis}

The current study used the CATPAC software for semantic network analysis. CATPAC is a self-organizing artificial neural network computer program for analyzing text (Terra Research and Computing, 1994). By using CATPAC, coder judgments or crude categories are not needed; rather, CATPAC establishes the categories that emerge from the data themselves (Danowski, 1992). In this study, the titles and abstracts from ComAbstracts between 1991 and 2005 were analyzed. The software identifies the most frequently occurring words in the text and determines the pattern of the co-occurrence of the words.

CATPAC was also used to generate word clusters, a process that has been employed in existing studies using

\footnotetext{
${ }^{3}$ Even though "analysis of issues and problems" may not be recognized as a "method" by some readers, we employ this concept as one of "methods" for the current study following Kim and Weaver (2002). According to them, "analysis of issues and problems" include summary and systematic analysis of Internet-related issues, concept or model building, comparative analysis, and comprehensive literature review and bibliographies. We adopted this category because we agreed to Kim and Weaver's justification, and there were studies which cannot be included in other categories.
}

semantic networks (Doerfel \& Barnett, 1999; Kim, Su, \& Hong, 2007; Rice, 2005; for more detailed description of the modules in the CATPAC engine see Rosen, Woelfel, Krikorian, \& Barnett, 2003).

In this study, CATPAC processed groups of titles and abstracts. Several "stop words" including articles, prepositions, conjunctions, and transitive verbs are excluded from analysis. Users may use their own discretion to unify some words that are used inconsistently (e.g., "web," "world wide web," and "www" are changed to "Web"). CATPAC then determines the frequency of occurrence (Doerfel \& Barnett, 1999; Rice, 2005). This study limited its scope to the top 50 most frequent words. It creates a word-by-word matrix in which the value of each cell is the probability of the co-occurrence of two words. CATPAC extracts clusters using this matrix and presents them in the form of a dendogram. Peaks in the dendogram represent central clusters (Doerfel \& Barnett, 1999). The valleys between the peaks represent the division of word groups (Woelfel, 1993).

The usage of CATPAC in this study is commensurate with Doerfel and Barnett (1999), and Kim, Su, and Hong (2007), and Rice (2005).

\section{RESULTS}

\section{Categorical Content Analysis}

\section{Developmental Phases of Research}

As Wimmer and Dominick (2000) suggested, the Internet-related research was categorized into four different research phases. Overall, the largest number of studies concerned the social or psychological effects of the Internet (Phase 3, 40.75\%) followed by use and perceptions (Phase 2, $38.63 \%$ ), issues about Internet itself (Phase 1, $16.30 \%$ ), and new directions for improving Internet research (Phase 4, 4.32 $\%)$.

Fig. (1) shows the percentage of research that belongs to each phase in each year from 1991 to 2005. Two general trends were found. First, research in phases 1 and 2 
Table 1. Top 10 Most Frequently Discussed Internet and New Media Topics From 1991 To 2005

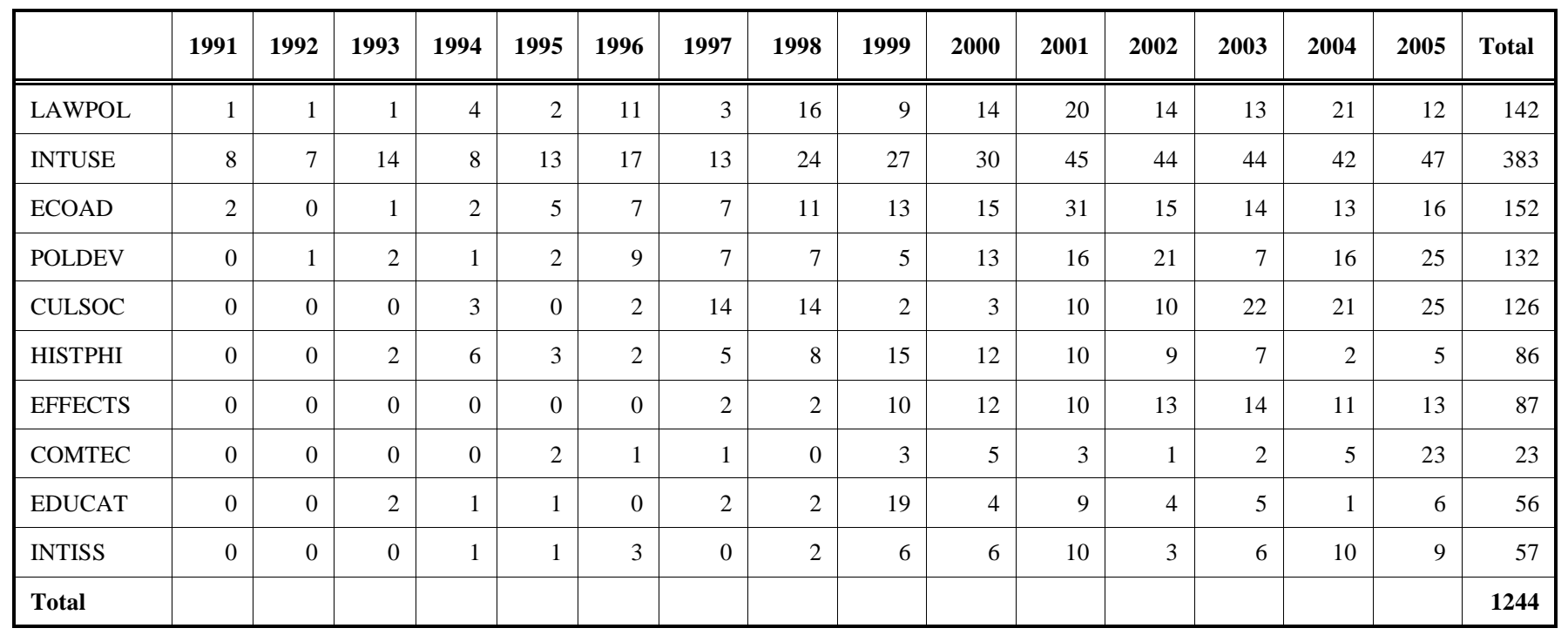

Note. The column indicates the frequency of articles in each year.

flourished from 1991 to 1996, and then continuously decreased over time; whereas research in phases 3 and 4 began to emerge from 1996 to 1998 . Phase 3 saw its peak from 2000 to 2003 . Phase 4 is still at its sprouting stage. Second, research from one phase to another did not appear in a linear fashion. Fig. (1) indicated that research in phases 1 and 2 was simultaneously conducted in the early days of new media research from 1991 to 1995 . Also, many scholars have continued to conduct research on uses and perceptions, even until 2005.

\section{Research Topics}

The topic that has attracted the most scholarly attention is the use and perception of Internet and new media $(29.99 \%$, e.g., Flanagin \& Metzger, 2001), followed by economic, advertising and marketing issues $(11.90 \%$, e.g., Chuang \& Sirbu, 1999), law and policy (11.12\%, e.g., Roodenburg, 2001), politics, democracy, and development issues (10.34 $\%$, e.g., Johnson \& Kaye, 1998), and cultural and social issues $(9.87 \%$, e.g. Sheehan, 1999).

Table 1 presents the changing nature of scholarly interests in new media research from 1991 to 2005 based on the top 10 topics. Uses and perception has been the most frequently discussed topic. Politics/development issues, economic/marketing issues, and effects of the new media have continuously increased over time. Other minor themes include technical issues in general $(2.36 \%$, e.g. Mason, $1998)$ and issues about Internet research trends (3.99\%, e.g. Kim \& Weaver, 2002), historical and philosophical discussion $(6.44 \%)$, effects of Internet on individual or organizations $(6.93 \%)$, and instructional application and distance learning $(5.05 \%)$.

\section{Theoretical Backgrounds}

Previous literature suggests that a majority of research is not based on a specific theoretical framework (Cooper et al., 1994; Kim \& Weaver, 2002). In line with this argument, this study found that only 145 out of $1,227(11.35 \%)$ employed a clearly identifiable theoretical framework. Table 2 indicated that the most frequently applied theory was the uses and gratifications theory $(17.24 \%$, e.g. Flanagin \& Metzger, $2001)$, followed by diffusion/adoption theory $(11.72 \%$, e.g. Lin, 2001), social identity theory $(11.03 \%$, e.g. Spears \& Lea, 1994), social presence theory (10.34 \%, e.g. Papacharissi \& Rubin, 2000) and theories regarding social influence $(6.90 \%$, e.g. Schmitz \& Fulk, 1991). There were some additional theories that were not frequently employed, including the stakeholder theory (e.g. Coombs, 1998) and compulsive buying theory (e.g. Larose \& Eastin, 2002).

\section{Methodologies Used}

Our findings show that qualitative methods were used more frequently than quantitative for new media research (Table 3). Regarding the specific methodology used, analysis of issues and problems was the most frequently used (28.69 $\%$, e.g. Chuang \& Sirbu, 1999), followed by historical or philosophical analysis (15.08 \%, e.g. Guice, 1998), experiments (12.80 \%, e.g. Spears \& Lea, 1994), and traditional (offline) surveys $(9.37 \%$, e.g. Flanagin \& Metzger, 2001). Research approaches that used several different methodologies in one study represented only a small portion of research $(2.53 \%$, e.g. Hampton \& Wellman, 1999). Interestingly, offline surveys $(9.37 \%)$ were used almost three times as much as online surveys $(2.85 \%$, e.g. Yu, Fulk, Shumate, Peter, Alison, \& Matthew, 2005).

\section{Semantic Network Analysis}

The word frequency analysis of the abstracts from 1991 to 2005 show that a group of broad concepts related to new media and information technology were highly ranked; information, communication, new, social, online, media, technology, Internet, public, and news were the top 10 items. The other words in the top 50, represented here in frequencydescending order, reveal that research stems from a diverse set of interests: relations, political, groups, television, model, effects, organizations, newspapers, health, community, cultural, world, computer, perceptions, role, issues, knowledge, time, development, support, policy, digital, influence, process, people, self, discourse, impact, and 
Table 2. The Application of Theories in Internet and New Media Research From 1991 to 2005

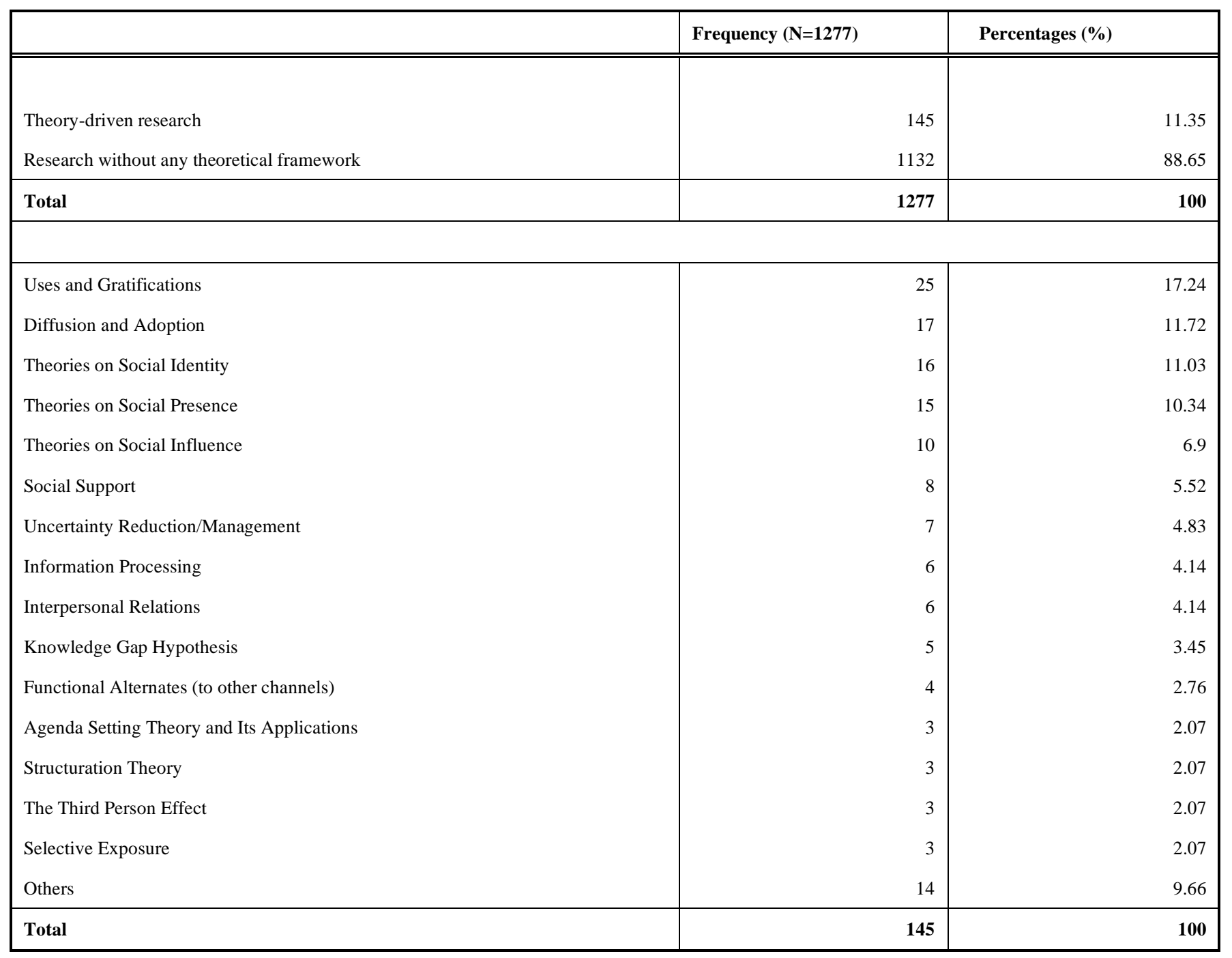

Note. Theories and methodologies coded for Table 1 and 2 are based on Wimmer and Dominick (2000), Kim and Weaver (2002), and a pilot study by the authors.

Table 3. The Application of Methodologies in Internet and New Media Research From 1991 to 2005

\begin{tabular}{|c|c|c|}
\hline Method Employed & Frequency $(\mathrm{N}=1277)$ & $\begin{array}{l}\text { Percentage } \\
(\%)\end{array}$ \\
\hline Qualitative Research Method & 769 & 62.67 \\
\hline Quantitative Research Method & 436 & 35.53 \\
\hline Total & 1277 & 100 \\
\hline Analysis of Issues and Problems & 352 & 28.69 \\
\hline
\end{tabular}


Table 3. contd...

\begin{tabular}{|c|c|c|}
\hline Method Employed & Frequency $(\mathrm{N}=1277)$ & $\begin{array}{l}\text { Percentage } \\
(\%)\end{array}$ \\
\hline Traditional Survey & 115 & 9.37 \\
\hline Content Analysis & 85 & 6.93 \\
\hline Secondary Dataset Analysis & 82 & 6.68 \\
\hline Legal Analysis (Cases) & 49 & 3.99 \\
\hline Discourse Analysis & 44 & 3.59 \\
\hline Online Survey & 35 & 2.85 \\
\hline Ethonography & 32 & 2.61 \\
\hline Cultural Studies & 13 & 1.06 \\
\hline Social Network Analysis & 12 & 0.98 \\
\hline Focus Group Interview & 8 & 0.65 \\
\hline Others & 7 & 0.57 \\
\hline Total & 1277 & 100 \\
\hline
\end{tabular}

survey. It was also found that some of the top 50 most frequent words are too general or less significant: related, studied, analysis, results, theory, data, levels, work, different, and findings.

A longitudinal analysis of the overall usage of the top 50 most frequent words from 1991 to 2005 (combined) shows that new technological words emerged as keywords. For example, "Internet" first emerged among the words listed in 1995. "Online" and "Digital" debuted in 1997 and 1999, respectively. The overall occurrence of the top 50 words was just 598 in 1991. However, the use of these words increased drastically from $1998(2,122)$ to $2005(5,250)$, indicating the rapid increase in the quantity of research in new media and the Internet.

The dendogram of the top 50 words from 1991 to 2005 (combined) denotes that the abstracts analyzed produced two large clusters based on hierarchical modeling. The larger one (Cluster 1) includes a series of keywords related to social aspects (social, public, organizations, groups, influence, people, and relations), but the words in Cluster 2 are mainly related to issues and policy processes (issues, discourse, knowledge, policy, process, health). These two traits (clusters) summarize the social and issue-focused nature of Internet/new media studies on a more macro level.

On the other hand, an analysis of the top 50 words of individual years from 1991 to 2005 shows that keyword frequency reflects the changing communication trends, as well as external conditions. See Table 4 for a representation of technological trends. "CMC" (computer-mediated communication) emerged as a frequent word in 1993, but disappeared in 1999. Likewise, the word "computer" disappeared in 2002. However, "Internet," which emerged in
1995, maintained a top 10 ranking through 2005. In contrast, the frequency of the word "news" has fallen from third (1992) and fourth (1991) to tenth in rank in 2005. Uses of the word "newspaper" disappeared from the top 10 list in 1993.

Appendix I indicates that the semantic network of each year has three to five clusters $(M=4.07, \mathrm{SD}=0.80)$. Results show that political topics (15), media effect (9), group dynamics (11), CMC (10), and communication technology (12) are most frequently found clusters throughout 19912005. Although 1991 has three clusters, one cluster (Cluster 1) has two related topics from subcategories, health and media (AIDS-press, children-computer-film). Likewise, 1992 has Cluster 3, which is related to both communication technology and group: computer-groups-influenceelectronic. These two examples indicate that the number of clusters is not always commensurate with the number of related topics.

\section{DISCUSSION}

\section{Interpretation of Findings}

The current study provides an analysis of the Internet and new media research that succeeds and develops Kim and Weaver's (2002) categorical content analysis, Wimmer and Dominick (2000), and Rice's semantic network analysis (2005). Instead of employing only one method (either categorical or semantic), this study provides more integrated perspectives on the general trends of Internet/new media research by using two methodological approaches simultaneously. Some findings support the previous literature; however, there were new findings that were inconsistent with past research. In Kim and Weaver (2002), law and policy issues were the most common topic of research, followed by the uses and perceptions of the 
Table 4. Top 50 Most Frequent Words of Each Year: 1991-2005

\begin{tabular}{|c|c|c|c|c|c|c|c|}
\hline Pank & 1992 & 1993 & 1994 & 1995 & 1996 & 1997 & \\
\hline \begin{tabular}{|l|l|l|l}
2 & COMMUCATION \\
\end{tabular} & 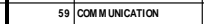 & 67 COMMUNICATION & \begin{tabular}{l|l|l|}
49 & COM MUNICATION \\
\end{tabular} & 54 MEDIA & COMMUNICATION & \begin{tabular}{|l|l|}
83 & MEDIA \\
\end{tabular} & 66 \\
\hline 3 TECHNOLOGY & 42 NEWS & $44 \sqrt{\text { EECHNOLOGY }}$ & 32 MEDOA & $\begin{array}{l}35 \text { COMMMUNICATION } \\
\end{array}$ & 40 TECHNOLOGY & \begin{tabular}{|l|l|}
$68 C H$ TEOLOGY \\
\end{tabular} & 58 \\
\hline 4 4 NEWS & \begin{tabular}{|l|l|}
39 & TECHNOLOGY \\
\end{tabular} & 33 MEDDAA & \begin{tabular}{l|l|l|l}
27 & TECHNOLOGY \\
\end{tabular} & 32 PUBLIC & $4 0 \longdiv { M E D I A }$ & \begin{tabular}{l|l|l|}
$48 F O R M A T I O N$ \\
\end{tabular} & 53 \\
\hline \begin{tabular}{|l|l|}
5 & STUDIED \\
\end{tabular} & 32 MEDAA & 26 TELEVISION & 22 NEWS & $\begin{array}{l}28 \\
28 E W \\
\end{array}$ & ANALYYSIS & $\begin{array}{ll}32 & \text { INTEERNET } \\
\end{array}$ & 46 \\
\hline \begin{tabular}{|l|l|}
6 & NEWSPAPERS \\
\end{tabular} & 30 PUBLIC & 28 NEWS & 21 PRIVACY & 28 NEWS & NEW & \begin{tabular}{l|l}
32 & ELECTRONIC \\
\end{tabular} & 43 \\
\hline 7 NEW & 28 NEW & $2 5 \longdiv { \text { MOOEL } }$ & $\begin{array}{l}20 \text { NEW } \\
20\end{array}$ & \begin{tabular}{l|l}
25 & TECHNOLOGY \\
\end{tabular} & 35 COMPUTER & 30 COMAUNICATION & $\overline{42}$ \\
\hline $\begin{array}{l}8 \text { MEDIA } \\
\text { 9 }\end{array}$ & \begin{tabular}{l|l|l|l|}
26 & RESEAACH \\
\end{tabular} & 24 COM PUTER & $\begin{array}{l}19 \text { STUOED } \\
\end{array}$ & $\begin{array}{ll}25 & \text { TELEVISION } \\
\end{array}$ & 33 NEWS & \begin{tabular}{|l|l|l|l|l|l|l|l|}
29 & STUDD \\
\end{tabular} & 35 \\
\hline 9 PUELIC & $\begin{array}{l}24 \\
\text { THEORY }\end{array}$ & 22 EFFECTS & $\begin{array}{ll}18 \text { RESEAACH } \\
\end{array}$ & 24 STUDIED & 30 GROUPS & 27 CULTURAL & 34 \\
\hline $\begin{array}{l}10 \text { |INFLLUENCE } \\
\end{array}$ & \begin{tabular}{ll|l}
22 & NEWSPAPERS \\
\end{tabular} & $\begin{array}{l}19 \text { STUDIED } \\
\end{array}$ & \begin{tabular}{|l|l|}
18 & ELECTRONCC \\
\end{tabular} & \begin{tabular}{l|l|l}
23 & ANALLYSIS \\
\end{tabular} & 26 POLITICAL & $\begin{array}{l}27 \\
2\end{array}$ & $\frac{30}{30}$ \\
\hline 11 SOCALL & \begin{tabular}{l|l|l|}
19 & STUDIED \\
\end{tabular} & 19. VEW & \begin{tabular}{|l|l|}
17 & ARGUES \\
\end{tabular} & 19 MOOEL & 26 STUDIED & \begin{tabular}{|l|l|}
26 & ARGUES \\
\end{tabular} & 28 \\
\hline 12 ANALLSIS & 17 COMPUTER & 18 GROUPS & 16 PUBLIC & 19 GROUPS & 25. 2 RGUES & 24 NEWS & 25 \\
\hline 13 CHLDREN & \begin{tabular}{|l|l|}
17 & ORGANIZATIONS \\
\end{tabular} & \begin{tabular}{|l|l|l|l|l|}
18 & ELCNIC \\
\end{tabular} & $\begin{array}{l}14 \\
\end{array}$ & $\begin{array}{l}18 \text { RELLATIONS } \\
\end{array}$ & NTERNET & 23 POLITICAL & $\frac{24}{24}$ \\
\hline \begin{tabular}{|l|l|l|}
14 & ELECTRONIC \\
\end{tabular} & \begin{tabular}{l|l|l|}
14 & ARGUES \\
\end{tabular} & $17 /$ MEDATED & 14 ANALYYSIS & \begin{tabular}{ll|l|l|l|l}
17 & SOCAL \\
\end{tabular} & 23 pUELC & 22 SCHOAARLY & 24 \\
\hline 15 RESEAACH & 14 TELEVISION & $17 \sqrt{\text { MESSAGES }}$ & 14 COMPUTER & $\begin{array}{ll}17 & \text { EFFECTS } \\
\end{array}$ & 21 OISCUSSES & 17 CUL TURE & 23 \\
\hline \begin{tabular}{l|l|l|}
16 & DEVELOPMENT \\
\end{tabular} & $\begin{array}{ll}\text { ELECTRONIC } \\
\end{array}$ & 16 NEWSPAPERS & 14 EFFECTS & $\begin{array}{l}16 \text { COMIPUTER } \\
\end{array}$ & 20 ELECTRONIC & $\begin{array}{l}17 \text { RESEARCH } \\
\end{array}$ & $\overline{22}$ \\
\hline \begin{tabular}{l|l|l|}
17 & MALL \\
\end{tabular} & \begin{tabular}{l|l|l|}
13 & EFFECTS \\
\end{tabular} & 15 RESULTS & \begin{tabular}{l|l|l|l|} 
NEWSPAPERS \\
\end{tabular} & \begin{tabular}{|l|l|l|}
15 & ORANIZATIONS \\
\end{tabular} & NEWSPAPERS & \begin{tabular}{|l|l|}
17 & TELEVISION \\
\end{tabular} & 22 \\
\hline \begin{tabular}{l|l|}
18 PERCEPTIONS \\
\end{tabular} & \begin{tabular}{l|l|l|l|l|l}
13 & STORIES \\
\end{tabular} & 15 DATA & $13 \sqrt{\text { ROLE }}$ & 15 NEWSPAPERS & 18 conMUNTYY & \begin{tabular}{|l|l|}
16 & GROUPS \\
\end{tabular} & 20 \\
\hline $\begin{array}{l}19 \\
\end{array}$ & 13 ANALLSIS & 14 PUBLIC & $\begin{array}{l}3 \text { TELEVISION } \\
\end{array}$ & $\begin{array}{l}15 \\
\text { RELLATED }\end{array}$ & 18 COLIURALL & 16 WORLD & $\overline{20}$ \\
\hline \begin{tabular}{|l|l|l|}
20 & ARGGUES \\
\end{tabular} & 12 SOCCAL & 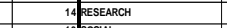 & 13 CMC & 14 ARGUUES & FFECTS & $\begin{array}{ll}16 & \text { ACADEEMIC } \\
\end{array}$ & 19 \\
\hline 21 LEVELS & 12 MARKET & SOCALA & \begin{tabular}{|l|l|l|}
13 & RESUULTS \\
\end{tabular} & 13 STRATEGES & ACE & 16 BroADCASTING & \\
\hline \begin{tabular}{l|l}
22 & TELEVISION \\
\end{tabular} & $\begin{array}{l}12 \text { PRESS } \\
\end{array}$ & 12 anc & \begin{tabular}{l|l|}
12 & ACCESS \\
\end{tabular} & \begin{tabular}{l|l}
12 & ELECTRONC \\
\end{tabular} & 16. & ${ }_{16}$ DIISCOURSE & $\overline{18}$ \\
\hline $\begin{array}{ll}23 & \text { AlDS } \\
\end{array}$ & 11 RECALL & 12 POLITICAL & \begin{tabular}{|l|l|l|l}
2 & FUUURE \\
\end{tabular} & \begin{tabular}{l|l|l|}
12 & RESEAACH \\
\end{tabular} & 16 RELATIONS & $\begin{array}{l}16 \text { NEWSPAPERS } \\
\end{array}$ & 17 \\
\hline 24 COVERAGE & $\begin{array}{l}11 \text { ISSUES } \\
\end{array}$ & 11 DISCUSSES & 10 GROUPS & 12 SURVEY & MEDDATED & $\begin{array}{l}15 \\
\text { ADVERTISING }\end{array}$ & 16 \\
\hline $\begin{array}{l}25 \\
2 \text { PEOPLE } \\
\end{array}$ & $11 /$ MEMORY & 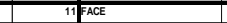 & \begin{tabular}{l|l|}
10 & IIIPACT \\
\end{tabular} & \begin{tabular}{l|l|l|l}
12 & KNOWLEDGE \\
\end{tabular} & POLCY & 15 CanAaDIAN & $\frac{16}{16}$ \\
\hline $\begin{array}{l}26 \text { POLITCAL } \\
277 \text { OISCUSSES }\end{array}$ & \begin{tabular}{|l|l|}
11 & CONFLLCT \\
\end{tabular} & 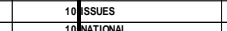 & $\begin{array}{l}10 \text { POLCY } \\
10 \text { ACE }\end{array}$ & \begin{tabular}{l|l|}
12 & PERCEPTIONS \\
\end{tabular} & 15 PRIVACY & $\begin{array}{l}15 \text { CYBEASPACE } \\
\end{array}$ & 16 \\
\hline$\frac{27 \text { DISCUSESS }}{28 \text { EFFECTS }}$ & $\begin{array}{l}10 \text { GOVERNM ENT } \\
10 \text { HEALTH }\end{array}$ & & \begin{tabular}{l|l|l|l|l|}
10 & AGE \\
10 & DEVELOPMENT
\end{tabular} & $\begin{array}{l}11 \\
11 \text { IISCUSLUENCE }\end{array}$ & $\begin{array}{l}14 \text { SOCIAL } \\
14 \text { SOCIETY }\end{array}$ & $\begin{array}{l}15 \text { DEVELOPMENT } \\
15 \text { NATIONAL }\end{array}$ & $\frac{16}{16}$ \\
\hline $\begin{array}{l}28 \text { EFFECTS } \\
29\end{array}$ & 9 MEDIATED & 10 RELATED & 10 DISCOUASE & 11 POLITICAL & 14 THEOAY & $\frac{15 \text { SOCALAL }}{15}$ & $\frac{16}{16}$ \\
\hline 30 MOOEL & 9 PERCEPTIONS & 10 RELATIONSHIP & 10 HICGWAY & 11 THEOAYY & 14 MPACT & 14 TRADITIONAL & 16 \\
\hline \begin{tabular}{l|l|l}
31 & RECALL \\
\end{tabular} & 9 PROCESSING & 10 ANALLYSIS & \begin{tabular}{l|l|l|}
9 & ISSUES \\
\end{tabular} & $\begin{array}{l}11 \text { CULTURE } \\
\end{array}$ & 13 STRATEGES & \begin{tabular}{l|l|l|l|l|}
14 & FUTURE \\
\end{tabular} & $\overline{15}$ \\
\hline \begin{tabular}{l|l|}
32 & ROLE \\
\end{tabular} & \begin{tabular}{l|l}
9 TIME \\
\end{tabular} & 10 CHANGE & 9 UNCERTAINTY & 11 PRESS & FELEVISION & \begin{tabular}{ll|l|}
14 & INDUSTRYY \\
\end{tabular} & 15 \\
\hline \begin{tabular}{l|l}
33 & STRATEGES \\
\end{tabular} & 9 AIDS & CULTURAL & \begin{tabular}{c|c|c|}
9 & ORGANIZATIONS \\
\end{tabular} & 10 GOVERNMENT & CAMPAIGN & \begin{tabular}{|l|l|}
13 & ISSUES \\
\end{tabular} & 15 \\
\hline $\begin{array}{l}34 \text { CHANGE } \\
\end{array}$ & 8 COCGNITIVE & NTERPERSONAL & 9 PERCEPTIONS & 10 INTERACTIVE & $12 \operatorname{anc}$ & 11 1 ROLE & $\overline{15}$ \\
\hline 35 COMPUTER & 8 GROUPS & JOURNALISTS & 9 POLITICAL & \begin{tabular}{|l|l|}
10 & SPEECH \\
\end{tabular} & 12 DATA & \begin{tabular}{|l|l|l|l|l}
1 & VIRTUAL \\
\end{tabular} & 15 \\
\hline 36 Looks & 8 IIIPACT & NNOWLEDGE & 9 POWER & 10 AGE & 11 DEVELOPMENT & 11 PUBLIC & $\frac{14}{14}$ \\
\hline 37 ORGANIZATIONS & 8 |IMPLICATIONS & Drganzations & \begin{tabular}{l|l|l|} 
RELLATIONSHIP \\
\end{tabular} & 10 DEVELLPMENT & 11 SSUES & 11 SUGGESTS & $\overline{13}$ \\
\hline 38 PRESS & $\begin{array}{l}8 \text { INELUENCE } \\
\end{array}$ & PRESENCE & $\begin{array}{l}9 \text { SOCIETY } \\
\end{array}$ & 10 IIIPACT & 11 RoLE & 11 THEOPY & 13 \\
\hline 39 PROCESSING & 8 MALL & Douestions & $\begin{array}{l}9 \text { SOURCES } \\
\end{array}$ & 10 | ISSUES & 11 SELF & 11 CHANGE & 12 \\
\hline $\begin{array}{l}40 \\
4 \text { SOUACES }\end{array}$ & $\begin{array}{l}\text { /MANAGEMENT } \\
\end{array}$ & SUPPORT & 9 TTHREE & $\begin{array}{l}10 \text { RESULITS } \\
\end{array}$ & SUGGESTS & 11|Economic & $\overline{12}$ \\
\hline $\begin{array}{l}\frac{41}{41} \text { SUBJECTS } \\
42 \text { SUGGESTS }\end{array}$ & 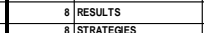 & SURVEY & 9 WAAR & \begin{tabular}{r|l|}
10 & SCIENCE \\
9 & AMERECAN \\
\end{tabular} & 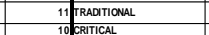 & \begin{tabular}{c|c|}
11 & FACE \\
10 & INTERATIOWAL \\
\end{tabular} & $\frac{12}{12}$ \\
\hline $\begin{array}{l}42 \text { SUGGESTS } \\
43 \text { SURVEY }\end{array}$ & $\begin{array}{l}8 \text { STSRATEGES } \\
8 \text { CONTROL }\end{array}$ & DAME & $\begin{array}{l}9.9 \text { ATTENIION } \\
8 \text { GOVERNMENT }\end{array}$ & $\begin{array}{l}99 \text { AMIERECAN } \\
9 \text { COVERAGE }\end{array}$ & $\frac{10 \text { CRPIICAL }}{10 \text { DIALOGUE }}$ & 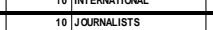 & $\frac{12}{12}$ \\
\hline $\begin{array}{l}44 \text { DISABLED } \\
\end{array}$ & 7 COVERAGE & HEALTH & \begin{tabular}{|l|l|}
8 & INTERACTION \\
\end{tabular} & 9 DECISION & Econoun Y & 10 ORGANIZATIONS & 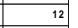 \\
\hline 45 EDITORS & \begin{tabular}{|l|l|l|}
7 INOUSTTYY \\
\end{tabular} & EEART & 8 JOURNALISM & 9 DIFFERENT & FAMILY & 10 POLICY & $\frac{12}{12}$ \\
\hline $\begin{array}{l}46 \\
\text { IMPPLICATIONS } \\
\end{array}$ & 7 IINTERPERSONAL & MPORTANT & 8 JOURNALISTS & 9 GENDER & 10 NFLUENCE & 10 PRESENCE & $\overline{12}$ \\
\hline \begin{tabular}{|l|l|}
$47 T E R P E R S O N A L$ \\
\end{tabular} & \begin{tabular}{l|l|l|l|l}
7 LEVELS & \\
\end{tabular} & AARTIIPATIION & 8 MEDAATED & $\begin{array}{l}9 \\
\text { INTERENET } \\
\end{array}$ & \begin{tabular}{l|l|l|}
10 NIERPERSONAL \\
\end{tabular} & $\begin{array}{l}10 \\
10 \text { RELATIONS } \\
\end{array}$ & 12 \\
\hline $\begin{array}{l}48 \text { MASSMEDIA } \\
\end{array}$ & 7 PART & PERCEPTIONS & 8 NEED & 9 LEAPNNG & MOOELL & 10 TIME & 12 \\
\hline $\begin{array}{l}49 \text { POWER } \\
\end{array}$ & 7 PERSONAL & PROCESS & 8 PROCESS & 9 ProCESS & 10 PRESIDENTIAL & \begin{tabular}{l|l|l}
10 & VALUES \\
\end{tabular} & 12 \\
\hline 50 PROBLEM & \begin{tabular}{|l|l|l|l}
7 RELATIONAL \\
\end{tabular} & 8) SOURCES & 8 SUANEY & \begin{tabular}{l|l}
9 & SOURCES \\
\end{tabular} & 10 Process & \begin{tabular}{|l|l|}
10 & Control \\
\end{tabular} & 11 \\
\hline
\end{tabular}

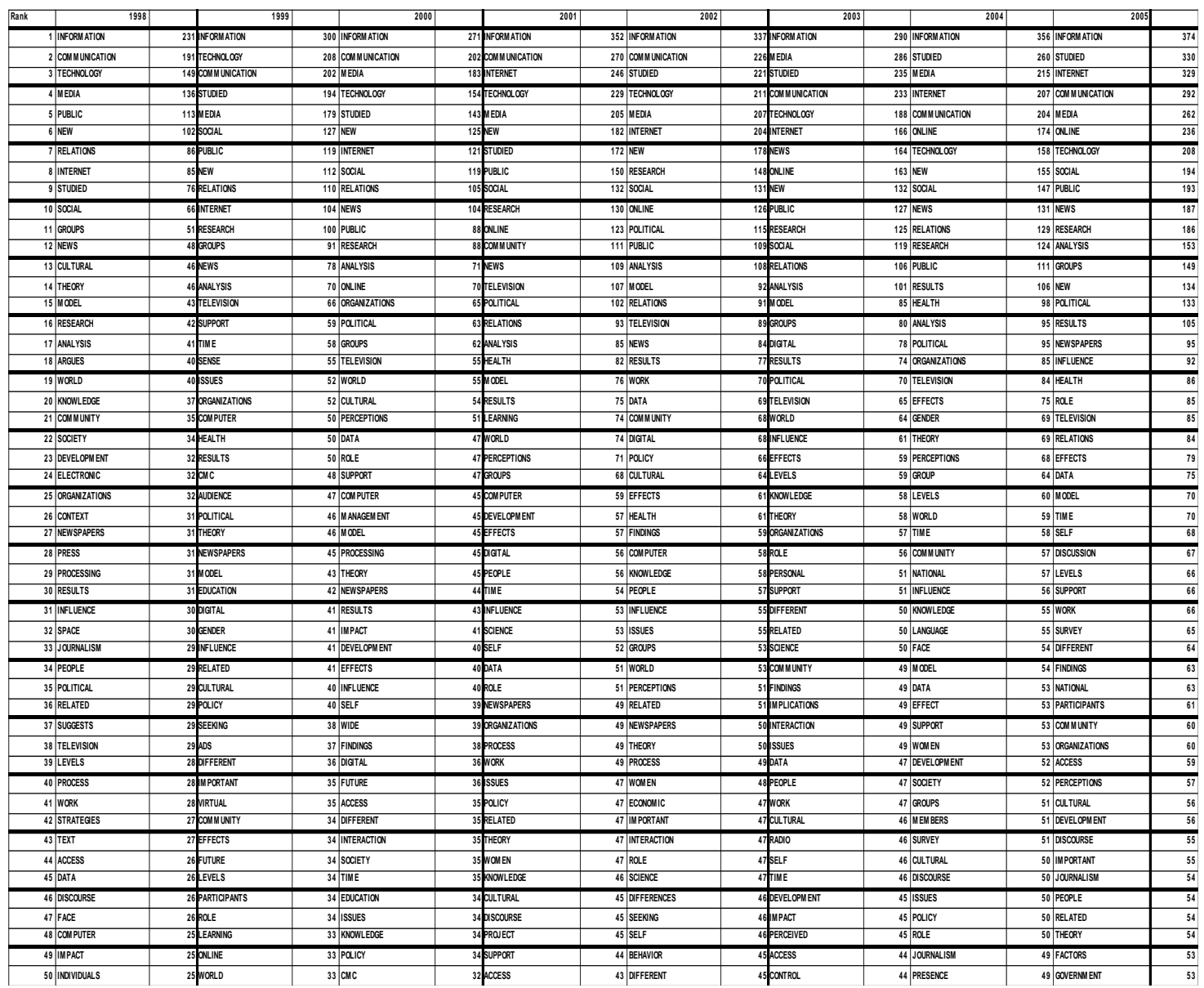

Note: The number on the right cell of each word indicates frequency. The cut-off of the $50^{\text {th }}$ ranked words was decided by CATPAC software and its ward's method algorithm. 
Internet. However, the findings of the current study suggest that uses and perceptions of the Internet were the most frequently discussed topics from 1991 to 2005.

There are two possible explanations for this difference. First, the difference derives from the fact that the current study uses an expanded time span compared to Kim and Weaver (2002), which covered from 1996 to 2000. The difference may also result from keywords used in both studies. Kim and Weaver (2002) limited their keywords to "Internet" and "World Wide Web" while the current study used more keywords as listed in the method section. In particular, inclusion of keywords such as "CMC" and "Information and Communication Technologies" may induce a different outcome. Many studies including these keywords were about the use and perception of the new media (e.g. Postumes, Spears, \& Lea, 2000). However, popular topics found in Kim and Weaver (2002) were also found in the current study. These topics include law and policy issues, use and perception, economic and advertising, political issues, and cultural and social issues. Topics related to political and development issues were found to be one of the frequently discussed issues in both the categorical and semantic network analyses. In this regard, scholars have paid continual attention to the Internet/ new media as new possible ways of political participation and campaigning (see D'Alessio, 2000).

Regarding Wimmer and Dominick's (2000) developmental model for the Internet-related research, a changing trend for each phase over time was clearly identified. Interestingly, most studies from 1991 to 1995 can be categorized as either Phase 1 or Phase 2 studies. However, since 1996, the numbers of studies in Phase 3 increased dramatically. The results of the semantic network analysis may provide valuable insights regarding this. Since the concept of the "Internet" was first introduced in 1995, its use has been considerably increasing over time (Table 3), which is in contrast to the concept of "CMC". CMC had been ranked among the top 50 most frequently used words in 1993, 1994 and 1996. However, its use has dramatically decreased since 1999, and did not rank in the top 50 keywords thereafter. Relating this to the developmental model, one possible interpretation is that "computer" and "mediated communication" based on it has been replaced by networkcentered (Internet, Web, and network) applications. Also, news and newspaper lost their central position over time.

The current study also found that few Internet and new media studies were driven by theoretical hypothesis testing as Kim and Weaver (2002) and Cho and Khang (2006) had pointed out. However, one notable trend was that beginning in 2000, more scholars started applying mass communication-based theoretical frameworks to Internet/new media related research (e.g., Third-person effect, Lo \& Wei, 2002; agenda setting, Roberts, Wanta, \& Dzwo, 2002).

Finally, this study found that more qualitative than quantitative studies have been conducted from 1991 to 2005. Among this qualitative research, analysis of issues and problems was the most frequently employed methodology, which is consistent with previous research (Kim \& Weaver, 2002).
Interestingly, the online survey method was not as popular in new media/ Internet research $(2.85 \%)$ as the traditional survey method $(9.37 \%)$, which reflects the difficulties in sampling, as Stempel and Stewart (2000) argued. In line with this finding, new advanced methodologies such as social network analysis have not yet been applied to many cases (see Garton, Haythornthwaite, \& Wellman, 1997 for an early description of this application). This may suggest that scholars prefer sticking to traditional methodologies to trying out new methodological approaches in Internet and new media research.

\section{Implication for Communication/Media Scholars}

The findings lead to several practical implications. First, although a theoretical approach has been stressed before the advent of Internet, studies based on a salient theoretical framework were not as frequent as those without. Such weakness in research invites another series of problems in that the absence of a theoretical diagnosis of Internet leads to failure in predicting its future, as seen from the salient shortage of Phase 4 (Wimmer \& Dominick, 2000) studies found from this research. Information technology experts currently discuss the future of Internet with such words as Web 2.0 and Web 3.0. However, communication scholars are still using older theories, such as uses and gratifications, which may fall short of covering all the agendas related to network media. For instance, ubiquitous Internet platforms make it hard to differentiate Internet use from social life. Further, young generations are meeting friends while simultaneously doing their homework at Internet cafés, indicating a more complex mix of communication of technology.

Second, the findings lead to a call for methodological diversification. The prevalence of qualitative methodologies does not suggest that there are any problems in method use. Rather, the authors argue that communication scholarship needs more diversity than the dominance of issue/problembased approach, experiments, and traditional survey. Communication scholarship needs to take advantage of available new methods, such as social network analysis (SNA). SNA is a fitting methodology for this context in that it can simultaneously cover multilateral interactions (social network) in the network environment, as well as individual level analyses (ego-network). Using SNA, researchers can expand the scope of research to predict multilateral actions on the Web with a wide variety of network analytic techniques, such as quadratic assessment procedures (see Barnett, Chon, and Rosen, 2001). Likewise, conventional discourse analysis may be combined with semantic network analysis by doing an analysis of words within texts based on their relationships (Monge \& Eisenberg, 1987). Communication technologies allow users to manage the resources in their social networks in unique ways, so studying them as social networks is a natural fit.

On the other hand, in cyberspace even personal messages (e.g. journals and blogs) have the potential of becoming public discourse if it is shared by Internet users on the Web. For instance, a personal blog post can invite an emotional response from numerous Internet users regardless of the blogger's intentions, including their intention to share it with a limited number of people. Even if something is intended to 
be shared with few people, these public posts can sometimes invite massive responses, which indicates a transformation of personal utterance to mass media. In this case, traditional content analysis of blog posts is not enough; this study leads to a call for new methodological approaches that focus on the relational or diffusion aspect of blog interactions. Blog hyperlink networks are an example of such a methodology (see Park \& Thelwall, 2008 for explication of hyperlink analysis). In doing this sort of research, for instance, scholars should track the activities of linking, trackbacking or commenting on the $\mathrm{Web}$, rather than relying only on the content alone.

\section{Conclusion and Suggestions for Future Research}

Previous analyses of Internet and new media research have a number of shortcomings. Most existing studies do not cover comprehensive time frame (mainly up to the late 1990s), use limited keywords for searching relevant studies, and employ homogeneous methods and few sources (limited numbers of journals) (Cho \& Chuang, 2006; Kim \& Weaver, 2002; Rice, 2005; Tomasello, 2001). The current study provided a more integrated picture of the general trends of Internet and new media research by extending the time period, using dual-methodologies, and including a wider scope of journal coverage.

Although the Internet itself has developed greatly and there has been much research on its social effects, few social-scientific theories have emerged only for Internet. This study suggested future research that focuses on the fourth phase of Wimmer and Dominick (2000) model. The fourth phase may lead to an establishment of "Internet theory," representing a new approach to Internet.

Additionally, future research should cover the most recent studies, as these reflect a rapidly changing landscape of communication technologies. New analyses might include key words reflecting current trends promoted by Internet and new media such as mobile communication, satellite radio, and I-phone, and include recent research on weblogs (Stefanone \& Jang, 2007) and social networking sites (Boyd, 2007, Ellison, Steinfield, \& Lampe, 2007, Kim \& Yun, 2007). A trend study in the future may also include more "critical" studies or macro studies on globalization without "research questions" or "hypothesis" for its analysis to cover as many studies as possible.

Communication technology has pervaded our social communicative world with uses and effects that can remain cloaked behind methodological abilities. Yet, social scientists will continue to seek explanations and predictions regarding the array of outcomes these processes produce from an expanding and improving set of theories and methods, and in a multitude of contexts.

\section{ACKNOWLEDGMENT}

We thank the editor of Open Communication Journal, Ms. Nadia Razzaque, and three anonymous reviewers for their precious comments and help. This work was supported (in part) by the Yonsei University Research Fund of 2009.

\section{APPENDIX}

Appendix I. Year-by-year clustering of Internet and New Media (Online Media) Research: 1991-2005

1991 (3 clusters)

Cluster 1: Health/Media (AIDS-PRESS, CHILDREN-COMPUTER-FILM)

Cluster 2: Political (POLITICAL-PEOPLE-TELEVISION-COVERAGE-PERCEPTIONS)

Cluster 3: Effect (NEWS-INTERPERSONAL-NEWSPAPERS-INFLUENCE-MEDIA-SOCIAL-PUBLIC)

1992 (5 clusters)

Cluster 1: Health/Interpersonal (AIDS-INTERPERSONAL-PERSONAL)

Cluster 2: Cognition/Media (COGNITIVE-MEMORY-PERCEPTIONS-RECALL-STORIES-CONTROL-GOVERNMENTTELEVESION)

Cluster 3: Commtech/Group (COMPUTER-GROUPS-INFLUENCE-ELECTRONIC)

Cluster 4: Effect (NEWSPAPERS-EFFECTS-ISSUES-SOCIAL)

Cluster 5: Media (PUBLIC-MEDIA-STRATEGIES-HEALTH-NEW-TECHNOLOGY-NEWS)

1993 ( 5 clusters)

Cluster 1: Political (AMERICAN-POLITICAL-CHANGE-MESSAGES-SUPPORT)

Cluster 2: Commtech/Journalism (CMC-NATIONAL-JOURNALISTS-NEWSPAPERS)

Cluster 3: Interpersonal/Commtech (RELATIONSHIP-PUBLIC-INTERPERSONAL-PRESENCE-SOCIAL)

Cluster 4: Communication technology (COMMUNICATION-INFORMATION-ELECTRONIC-TECHNOLOGY)

Cluster 5: Commtech/Effect (COMPUTER-MEDIATED- EFFECTS-NEWS-TELEVISION)

1994 ( 5 clusters)

Cluster 1: Effect (EFFECTS-SOCIAL-COMPUTER-PUBLIC)

Cluster 2: Communication technology (INFORMATION-TECHNOLOGY-MEDIA-NEW-SOCIETY-ELECTRONICPRIVACY) 
Cluster 3: Commtech (CMC-GROUPS-UNCERTAINTY-DISCOURSE-INTERACTION-MEDIATED)

Cluster 4: Journalism (JOURNALISM-JOURNALISTS)

Cluster 5: Political (POLITICAL-PROCESS-GOVERNMENT-TELEVISION-POLICY)

1995 (5 clusters)

Cluster 1: Political/Commtech (GOVERNMENT-AMERICAN-ELECTRONIC-INTERACTIVE-INTERNET)

Cluster 2: Group (CULTURE-DIFFERENT-INFLUENCE-PERCEPTIONS-PRECESS-DECISION-GROUPS)

Cluster 3: Communication technology (SOCIAL-INFORMATION-NEW-TECHNOLOGY-MEDIA)

Cluster 4: Political (GENDER-POLITICAL-ORGANIZATIONS)

Cluster 5: (COMPUTER-NEWSPAPERS)

1996 (4 clusters)

Cluster 1: Communication technology/Political (TECHNOLOGY-INFORMATION-MEDIA-NEW-COMPUTERPOLITICAL-NEWS-PUBLIC)

Cluster 2: Group (COMMUNITY-GROUPS-EFFECTS)

Cluster 3: Political (CAMPAIGN-DIALOGUE-FAMILY-PRESIDENTIAL)

Cluster 4: Commtech/Effect (CMC-PRIVACY-INTERPERSONAL-NEWSPAPERS-INFLUENCES-TELEVISION-IMPACTSOCIETY)

1997 (4 clusters)

Cluster 1: Political/Commtech (CULTURAL-POLITICAL-CYBERSPACE-ONLINE-NATIONAL)

Cluster 2: Communication technology (TECHNOLOGY, NEW-MEDIA-TRADITIONAL-ELECTRONIC-INTERNET)

Cluster 3: AD/PR (ADVERTISING-PRESENCE-PUBLIC-RELATIONS-TELEVISION-NEWSPAPERS)

Cluster 4: Journalism (ISSUES-CONTROL-JOURNALISTS-SOCIAL)

1998 (3 clusters)

Cluster 1: Group/Media (CONTEXT-PROCESS-GROUPS-INFLUENCE-NEWSPAPERS-ELECTRONIC-NEWS-SOCIETY)

Cluster 2: PR/Communication technology (INFORMATION-PUBLIC-RELATIONS-WORLD-COMMUNICATIONTECHNOLOGY-INTERNET-MEDIA)

Cluster 3: Group/Political (COMMUNITY-TELEVISION-POLITICAL-JOURNALISM-ORGANIZATIONS-PEOPLEDISCOURSE-PROCESSING)

1999 (4 clusters)

Cluster 1: AD/Political (ADVERTISEMENTS-SEEKING-AUDIENCE-PARTICIPANTS-GENDER-POLICY-POLITICALONLINE-TELEVISION)

Cluster 2: (NEWS-DIGITAL)

Cluster 3: Communication technology/Health (COMPUTER-INTERNET-INFORMATION-ISSUES-NEW-HEALTHMEDIA-TECHNOLOGY)

Cluster 4: Group/Commtech (CMC-COMMUNITY-SUPPORT-GROUPS-ORGANIZATIONS-VIRTUAL-INFLUENCE)

2000 (3 clusters)

Cluster 1: Media (CMC-INTERACTION-MANAGEMENT-DIGITAL-COMPUTER-NEWSPAPERS-TELEVISION)

Cluster 2: Communication technology (INTERNET-TECHNOLOGY-NEW-INFORMATION-PERCEPTIONS)

Cluster 3: Effect/Political (POLITICAL-INFLUENCE-ROLE-SUPPORT-IMPACT-ONLINE-PROCESSING-MEDIA-NEWS) 2001 (3 clusters)

Cluster 1: Political/Effect (EFFECTS-ISSUES-PROCESS-WOMEN-INFLUENCE-NEWSPAPERS)

Cluster 2: (DIGITAL-TELEVISION-WORLD)

Cluster 3: Communication technology/Group (NEW-TECHNOLOGY-ONLINE-MEDIA-INTERNET-SOCIALINFORMATION-POLITCAL-COMMUNITY-GROUPS-HEALTH-PUBLIC-SUPPORT)

2002 (4 clusters)

Cluster 1: Effect (BEHAVIOR-KNOWLEDGE-PERCEPTIONS-SEEKING-EFFECTS) 
Cluster 2: New Media (INFORMATION-ONLINE-INTERNET-MEDIA-NEW-PUBLIC-SOCIAL)

Cluster 3: Political/Group (WOMEN-CULTURAL-DIGITAL-GROUPS-PEOPLE-INTERACTION-INFLUENCE-PROCESS)

Cluster 4: (WORLD-TELEVISION)

2003 (4 clusters)

Cluster 1: Group/Media (DIGITAL-PERSONAL-ORGANIZATIONS-COMMUNITY-RADIO-TELEVISION-PERCEIVED) Cluster 2: Commtech/PR (ISSUES-SOCIAL-COMMUNICATION-TECHNOLOGY-INTERNET-ONLINE-PUBLICRELATIONS)

Cluster 3: Effect (INFLUENCE-SUPPORT-KNOWLEDGE-MEDIA)

Cluster 4: (INTERACTION-GROUPS-POLITICAL-NEW)

2004 (4 clusters)

Cluster 1: Communication technology/PR (INTERNET-SOCIAL-MEDIA-PUBLIC-NEWS -RELATIONS-INFLUENCE)

Cluster 2: Group (GROUPS-KNOWLEDGE-ORGANIZATIONS-MEMBERS-SUPPORT-LANGUAGE-PERCEPTIONSSOCIETY)

Cluster 3: (WORLD-COMMUNITY)

Cluster 4: Political (ISSUES-NATIONAL-POLICY-TELEVISION-WOMEN-GENDER-JOURNALISM)

2005 (5 clusters)

Cluster 1: Journalism (PERCEPTIONS-NEWSPAPERS-GOVERNMENT-JOURNALISM-PEOPLE)

Cluster 2: Political (NATIONAL-TELEVISION-DISCUSSION)

Cluster 3: (IMPORTANT-DISCOURSE)

Cluster 4: Communication technology (COMMUNICATION-TECHNOLOGY-COMMUNITY-SUPPORT-RELATIONSMEDIA-NEW)

Cluster 5: Group/Commtech (ORGANIZATIONS-GROUPS-ROLE-INFLUENCE-INTERNET-ONLINE)

\section{REFERENCES}

Anderson, J. A., \& Meyer, T. P. (1988). Mediated Communication: A Social Action Perspective. Newbury Park, CA: Sage.

Barnett, G. A., \& Kincaid, D. L. (1983). A Mathematical Theory of Cultural Convergence. In: Gudykunst, W. B. (Ed.), Intercultural Communication Theory. Current Perspectives (pp. 171-179). Beverage Hill, CA: Sage.

Barnett, G. A., \& Woelfel, J. (1988). Reading in the Galileo System: Theory, Methods and Applications. Dubuque, IA: Kendall/ Hunt.

Barnett, G. A., Chon, B., \& Rosen, D. (2001). The structure of the Internet Flows in Cyberspace. Networks and Communication Studies: NETCOM, 15, 61-80.

Bonchek, M. S. (1997). From Broadcast to Netcast: The Internet and the Flow of Political Communication. Doctoral dissertation in Harvard University.

Boyd, D. (2007). Why Youth (heart) Social Network Sites: The Role of Networked Publics in Teenage Social Life. In: Buckingham, D. (Ed.) MacArthur Foundation Series on Digital Learning- Youth, Identity, and Digital Media (pp. 119-142).Cambridge, MA: MIT Press.

Carley, K. (1991). A theory of group stability. American Sociology Review, $56,331-354$

Carley, K. M., \& Kaufer, D. S. (1993). Semantic connectivity: An approach for analyzing symbols in semantic networks. Communication Theory, 3, 183-213.

Caplan, S. E. (2001). Challenging the mass-interpersonal communication dichotomy: Are we witnessing the emergence of an entirely new communication system? The Electronic Journal of Communication, 11. [Retrieved March 5, 2005, from www.cios.org/www/ejc/v11n101.htm]

Cappell, C. L., Guterbock, T. M. (1992). Visible colleges: The social and conceptual structure of sociology specialties. American Sociological Review, 57(2), 266-273.

Cho, C. H., \& Khang, H. K. (2006). The state of internet-related research in communication, marketing, and advertising: 1994-2003. Journal of Advertising, 35, 143-163.

Collins, A. M., \& Quillian, M. R. (1972). Experiments on semantic memory and language comprehension. In: Gregg, L. W. (Ed.),
Cognition in Learning and Memory (pp. 117-138). New York: Wiley.

Coombs, W. T. (1998). The internet as potential equalizer: New leverage for confronting social irresponsibility. Public Relations Reviews, 24, 289-304.

Cooper, R., Potter, W., \& Dupagne, M. (1994). A status report on methods used in mass communication research. Journalism Educator, 48, 54-61.

Chuang, J. A., \& Sirbu, M. A. (1999). Optimal bundling strategy for digital information goods: Network delivery of articles and subscription. Information Economics and Policy, 11, 147-76.

D'Alessio, D. (2000). Adoption of the World Wide Web by American political candidates, 1996-1998. Journal of Broadcasting and Electronic Media, 44, 556-568.

Danowski, J. A. (1982). A network-based content analysis methodology for computer mediated communication: An illustration with a computer board. Communication Yearbook, 6, 904-925.

December, J. (1996). Units of analysis for Internet communication. Journal of Communication, 46, 14-38.

Doerfel, M. L., \& Barnett, G. A. (1996). The use of CATPAC for textual analysis. Cultural Anthropology Methods, 8, 4-7.

Doerfel, M. L., \& Barnett G. A. (1999). A comparison of the semantic and affiliation networks of the International Communication Association. Human Communication Research, 25, 589-603.

Dominick, J. R. (1999). Who do you think you are? Personal home page and self-presentation on the World Wide Web. Journalism and Mass Communication Quarterly, 76, 646-58.

Ellison, N. B., Steinfield, C., \& Lampe, C. (2007). The benefits of Facebook "friends:" Social capital and college students' use of online social network sites. Journal of Computer-Mediated Communication, 12(4), 1143-1168.

Flanagan, A. J., \& Metzger, M. J. (2001). Internet use in the contemporary media environment. Human Communication Research, 27, 153181.

Garton, L., Haythornthwaite, C., \& Wellman, B. (1997). Studying online social networks. Journal of Computer-Mediated Communication, 3(1). [Retrieved April 5, 2003, from www.ascusc.org/jcmc/vol3/issue $1 /$ garton.html] 
Guise, J. (1998). Looking backward and forward at the Internet. Information Society, 14, 201-12.

Hampton, K., \& Wellman, B. (1999). Netville online and offline: observing and surveying a wired suburb. American Behavioral Scientists, 43, 475-492.

Johnson, T. J., \& Kaye, B. K. (1998). Cruising is believing? Comparing Internet and traditional sources on media credibility measures. Journalism \& Mass Communication Quarterly, 75, 325-340.

Kim, S. T., \& Weaver, D. (2002). Communication research about the Internet: a thematic meta-analysis. New Media \& Society, 4, 518538 .

Kim, J. H., Su, T., \& Hong, J. (2007). The influence of geopolitics and foreign policy on the U.S. and Canadian media: An analysis of newspaper coverage of Sudan's Darfur conflict. Harvard International Journal of Press/Politics, 12, 87-95.

Kim, K. H., \& Yun, H. (2007). Cying for me, cying for us: Relational dialectics in a Korean social network site. Journal of ComputerMediated Communication, 13(1), article 15.

Krippendorf, K. (2004). Content Analysis: An Introduction to its Methoology. ( $2^{\text {nd }}$ ed.). Thousand Oaks, California: Sage.

Kuhn, T. (1970). The Structure of Scientific Revolutions. Chicago, IL: University of Chicago Press.

Lindlof, T. R., \& Taylor, B. C. (2002). Qualitative Communication Research Method. (2 ${ }^{\text {nd }}$ ed.). Thousand Oaks, California: Sage.

Larose, R., \& Eastin, M. (2002). Is online buying out of control? Electronic commerce and consumer self-regulation. Journal of Broadcasting and Electronic Media, 46, 549-564.

Lo, V., \& Wei, R. (2002). Third-person effect, gender, and pornography on the internet. Journal of Broadcasting and Electronic Media, 46, 13-33.

Lee, S. J., \& Barnett, G. A. (2005). Structural change in Communication between 1991 and 2005: A social and semantic network analysis of the International Communication Association. Paper presented to the $56^{\text {th }}$ annual convention of International Communication Association (ICA), Dresden, Germany.

Lin, C. A. (2001). Audience attributes, media supplementation, and likely online service adoption. Mass Communication \& Society, 4, 19-38.

Mason, R. (1998). Internet telephone and the International accounting rate system. Telecommunication Policy, 22, 931-44.

Monge, P. R., \& Eisenberg, E. M. (1987). Emergent communication networks. In: Jablin, F. M., Putnam, L. L., Roberts, K. H. and Porter, L. W. (Eds.), Handbook of Organizational Communication (pp. 304-342). Newbury Park, CA: Sage.

Morris, M., \& Ogan, C. (1996). The internet as mass medium. Journal of Communication, 46, 49-60.

Newhagen, J. E., \& Rafaeli, S. (1996). Why communication researchers should study the internet: A dialogue. Journal of Communication, 46, 4-13.

Nielsen/ NetRatings (2007). Nielsen/NetRating average Internet usage. Retrieved May, 15, 2007 from http://www.nielsen-netratings.com/news.jsp?section=dat_gi Internet World Stats (2006). Internet growth statistics. [Retrieved May, 15, 2007 from: http://www.Internetworldstats.com/emarketing.htm]

Papacharissi, Z., \& Rubin, A. M. (2000). Predictors of Internet use. Journal of Broadcasting and Electronic Media, 44, 175-196.

Park, H. W., \& Thelwall, M. (2008). Link analysis: Hyperlink patterns and social structure on politicians' web sites in South Korea. Quality \& Quantity, 42 (5), 687-697.

Park, H. W., \& Leydesdorff, L. (2009). Knowledge linkage structures in communication studies using citation analysis among communication journals. Scientometrics,81(1), 157-175.

Postumes, T., Spears, R., \& Lea. M. A. (2000). The formation of group norms in computer-mediated communication. Human Communication Research, 26, 341-371.

Reeves, B., \& Borgman, C. L. (1983). A bibliometric evaluation of core journals in communication research. Human Communication Research, 10, 119-136.
Rice, R. E., Borgman, C., \& Reeves, B. (1988). Citation networks of communication journals, 1977-1985: Cliques and positions, citation made and citation received. Human Communication Research, 15, 256-283.

Rice, R. E. (2005). New media/ Internet research topics of the Association of Internet Researchers. The Information Society, 21, 285-299.

Riffe, D., \& Freitag, A. (1997). A content analysis of content analyses: Twenty-five years of Journalism Quarterly. Journalism \& Mass Communication Ouarterly, 74, 515-24.

Roberts, M., Wanta, W., \& Dzwo, T. (2002). Agenda setting and issue salience online. Communication Research, 29, 452-465.

Rogers, E. M., \& Kincaid, D. L. (1981). Communication Networks: Toward a New Paradigm for Research. New York: Free Press.

Roodenburg, J. M. (2001). "Son of CDA": The constitutionality of the Child Online Protection Act of 1998. Communication Law and Policy, 6 , 227-257.

Rosen, D., Woelfel, J., Krikorian, D., \& Barnett, G. A. (2003). Procedures for analyses of online communities. Journal of Computer Mediated Communication, 8, 4. [Retrieved from http://www.ascusc.org/jcmc/vol8/issue4/rosen.html]

Schmitz, J., \& Fulk, J. (1991). Organizational colleagues, media richness, and electronic mail. Communication Research, 18, 487-523.

Sheehan, K. B. (1999). An investigation of gender differences in on-line privacy concerns and resultant behaviors. Journal of Integrative Marketing, 13, 24-38.

Shaw, D. L., Hamm, B. J., \& Knott, D. L. (2000). Technological change, agenda challenge and social melding: Mass media studies and the four age of place, class, mass and space. Journalism Studies, 1(1), 57-79.

Spears, R., \& Lea, M. (1994). Panacea or Panopticon? The Hidden Power in Computer- Mediated Communication. Communication Research, 21, 427-459.

Stefanone, M. A., \& Jang, C. Y. (2007). Writing for friends and family: The interpersonal nature of blogs. Journal of Computer-Mediated Communication, 13(1), 123-140.

Stempel, G. H. III., \& R. K. Stewart (2000). The Internet provides both opportunities and challenges for mass communication research. Journalism and Mass Communication Quarterly, 77, 541-48.

Stephen, T. (1999). Computer-assisted concept analysis of HCR's first 25 years. Human Communication Research, 25, 498-513.

Terra Research and Computing. (1994). The Galileo Computer Program [Computer software]. Birmingham, MI: Terra.

Tomasello, T. K. (2001). The status of Internet-based research in five leading communication journals, 1994-1999. Journalism and Mass Communication Quarterly, 78, 659-671.

U. S. Census Bureau. (2006). Quarterly retail e-commerce sales. [Retrieved May 15, 2007 from: http://www.census.gov/mrts/www/data/html/06Q3.html]

Weaver, D. H. (2000). Mass communication research at the end of the $20^{\text {th }}$ century: Looking back and ahead. Paper Presented to the International Conference of School of Journalism and Communication, Chinese University of Hong Kong, Hong Kong.

Wellman, B. \& Haythornthwaite, C. (Eds.) (2002). The Internet in Everyday Life. Oxford, UK: Blackwell Publishers.

Wimmer, R. D., \& Dominick, J. R. (2000). Mass Media Research (6 ${ }^{\text {th }}$ ed.) Belmont, CA: Wadsworth.

Woelfel, J. (1993). Artificial neural networks for policy research. Journal of Communication, 43, 63-80.

Woo, H. (2005). A consideration of developmental model in Korea Internet research between 1995-2005. Communication Theory [in Korean], $1,334-365$.

Yu, Y., Fulk, J., Shumate, M., Peter, M., Alison, B., \& Matthew, M. (2005). Individual participation in organizational information commons: The impact of team level social influence and technology specific competence. Human Communication Research, 31, 212-240. 